\title{
Organização e acesso às informações jurídicas
}

\begin{abstract}
Resumo
A área jurídica tornou-se campo importante de atuação dos bibliotecários, mas exige destes profissionais, especialização quanto às terminologias e conhecimento das fontes de informação específicas que permeiam este universo. $O$ objetivo deste artigo é apresentar as principais ferramentas de organização e acesso a informações jurídicas, com intuito de contribuir com o trabalho dos bibliotecários, com os estudantes e pesquisadores da área jurídica. Para alcançar o objetivo proposto foi realizado um levantamento das principais fontes de informação da área do Direito. Apresenta-se como resultado uma listagem com ferramentas para organização e recuperação da informação jurídica. Conclui-se que há disponibilidade de diversas fontes de informação em Direito; é preciso que o bibliotecário conheça essas fontes e adquira conhecimento sobre as terminologias e linguagem jurídica de forma a criar técnicas para a organização e gestão da documentação jurídica.
\end{abstract}

Palavras-chave: Direito; Fontes de informação jurídica; Informação jurídica; Organização da informação; Sistemas de recuperação da informação Direito.

\section{Cláudio Marcondes de Castro Filho}

Doutor em Ciência da Informação pela Universidade de São Paulo -

USP. Professor da USP.

Brasil

claudiomarcondes@ffclrp.usp.br

\section{Márcia Regina da Silva}

Doutora em Educação pela

Universidade Federal de São

Carlos - UFSCAR/SP. Professora da Univ. de São Paulo - USP.

Brasil

marciaregina@usp.br

\section{Geovana Canevari Costa}

Graduada em Biblioteconomia pela Univ. de São Paulo - USP.

Brasil

geovanaa_pb@hotmail.com

\section{Para citar este artigo:}

FILHO, Cláudio Marcondes de Castro; SILVA, Márcia Regina da; COSTA, Geovana Canevari. Organização e acesso às informações jurídicas. Revista PerCursos, Florianópolis, v. 17, n.33, p. 98 - 116, jan./abr. 2016.

\section{DOI: $10.5965 / 1984724617332016098$}

http://dx.doi.org/10.5965/1984724617332016098 


\title{
Organization and access to legal information
}

\begin{abstract}
The legal field has become an important field of expertise of librarians, but requires from these professionals especialization regarding the terminology and knowledge of the specific information sources that permeate this universe. The objective of this paper is to present the main organizing tools and access to legal information, aiming to contribute to the work of librarians, with students and researchers from the legal area. To achieve the proposed objective was conducted a survey of the main sources of information of the area of law. It presents as results a listing of tools for organization and retrieval of legal information. It is noteworthy that to gain knowledge about the use of the terminology, the legal language and information sources is possible to create technical librarian for the organization and management of legal documentation to facilitate the retrieval of information in manual or electronic mean.
\end{abstract}

Keywords: Law; Sources of legal information, Legal information; Information organization; Information retrieval systems - Law. 


\section{Introdução}

A organização da informação jurídica sempre exigiu dos profissionais da informação maior atenção no que se refere às especificidades e riqueza terminológica da área. As inovações dos formatos de registros da informação, embora tenham contribuído para o processo de organização, armazenamento e acesso à informação, não excluíram a necessidade de atuação e especialização do bibliotecário na área de Direito.

A preocupação com a organização da informação jurídica remonta às primeiras bibliotecas, como a Biblioteca de Alexandria, que já possuía uma classificação específica. A organização temática no campo jurídico teve alguns ilustres representantes, como Gesner (1545), que se dedicou a indexação de assuntos de doutrina e da legislação existente à sua época. A própria Classificação Decimal Universal (CDU), código até hoje utilizado para a classificação de obras jurídicas, foi elaborada por dois advogados belgas, Paul Otlet e Henri La Fontaine. (LIMA; CUNHA, 2008).

No Brasil, o interesse pela organização da informação jurídica não é tão recente; na década de 1970, a bibliotecária e professora Cordélia Robalino de Oliveira Cavalcanti, diretora do Centro de Documentação da Câmara dos Deputados e professora do Departamento de Ciência da Informação e Documentação da Universidade de Brasília, não mediu esforços para promover ações para a organização da informação jurídica e legislativa. Podemos considerá-la precursora desta área no país.

Já a disseminação das fontes de informação jurídica foi impulsionada com o advento dos computadores na década de 1980. Neste período, surgiram as primeiras bases de dados com informação jurídica no formato CD-ROM e, logo depois, tais bases foram disponibilizadas na Internet.

Este trabalho tem como objetivo apresentar as principais ferramentas de organização e acesso a informações jurídicas, com intuito de contribuir com o trabalho dos bibliotecários que atuam nesta área e com os estudantes e pesquisadores da área jurídica.

Trata-se de uma pesquisa do tipo exploratória e descritiva que teve como pressuposto levantar ferramentas para organização e recuperação da informação jurídica 
e fontes de informação jurídica em bibliotecas digitais, portais, revistas eletrônicas e sites jurídicos.

\section{Ferramentas para organização e recuperação da informação jurídica}

O papel do bibliotecário jurídico é facilitar o acesso à documentação jurídica, definir conceitos, coletar dados, criar métodos de busca, estratégias de leitura e fazer pesquisas para o usuário final. Ao adquirir conhecimento sobre o uso das terminologias e da linguagem jurídica, é necessário criar técnicas para a organização e gestão da documentação a fim de facilitar a recuperação da informação em diferentes meios, manuais ou eletrônicos.

A informação jurídica pode ser gerada, registrada e recuperada por meio de normativas, interpretativas e analíticas, ou seja, pela legislação, utilização da jurisprudência e doutrina (PASSOS; BARROS, 2009). A legislação (leis, decretos, decretosleis, atos, resoluções, portarias, projetos de leis, etc.), a jurisprudência (acórdãos, recursos, decisões e de todos os documentos relativos a atos normativos administrativos) e a doutrina constituem a massa da documentação jurídica (ATIENZA, 1979).

Já a organização da documentação jurídica envolve, além do conhecimento sobre a natureza e a estrutura dessa documentação, competências para realização do processo de indexação que tenha como principal objetivo representar o conteúdo dos documentos de forma precisa e mais próxima possível das necessidades de um público especializado. O processo de indexação envolve os procedimentos de leitura documentária e identificação documental, que são essenciais para que qualquer profissional ou especialista na área de documentação jurídica possa criar instrumentos e elaborar estratégias que permitam contribuir para a recuperação da informação. Para isso, há necessidade de compreensão dos domínios e terminologias que constituem os textos jurídicos.

A leitura documentária consiste, primeiramente, em fazer uma leitura técnica, reconhecer a estrutura textual do documento e, posteriormente, fazer uma análise do conteúdo, visando identificar, selecionar, sintetizar e organizar os conceitos para o processo de indexação da informação. 
O reconhecimento do documento que será indexado também se faz necessário; é preciso, por exemplo, diferenciar a natureza do documento, ou seja, se é uma fonte primária ou secundária, ou se é um documento legislativo, doutrinário ou jurisprudencial. Cada documento carrega uma linguagem, uma formatação e uma terminologia específica.

A leitura documentária deve ser planejada; as estratégias de leitura profissional envolvem o conhecimento prévio da área, a compreensão textual e a definição de objetivos de leitura. Cabe ao indexador criar meios estratégicos para a interpretação e a representação do conteúdo dos documentos (KOCH, 2006).

Após o reconhecimento do documento jurídico e da linguagem utilizada, o indexador precisa elaborar estratégias e estabelecer critérios de busca para a recuperação de informação relevante que atenda suas necessidades. Dessa forma, a leitura documentária tem como objetivo descodificar a mensagem para que a mesma seja compreendida pelo leitor.

A linguagem documentária é um modelo de organização de termos, com a função de representar um conteúdo através da normalização dos significantes. Segundo Fujita (2004, p. 7),

uma linguagem documentária, também conhecida na literatura como linguagem de indexação, é um conjunto controlado de termos dotados de regras sintáticas e semânticas cujo objetivo é a representação de conceitos significativos dos assuntos dos documentos durante a indexação na fase de tradução e durante a busca a representação do assunto de interesse do usuário.

Em relação ao conteúdo representado pelas linguagens documentárias e vocabulários controlados, há especificidades de acordo com a temática abrangida. Um vocabulário controlado ou tesauro que representa um conteúdo da área de Direito Civil, por exemplo, não terá condições necessárias de representar a área de Direito Comercial. Ainda que tratem do mesmo campo do conhecimento, os termos e conceitos se diferem. Há conceitos que se aplicam de forma diferente nas diversas áreas, de acordo com os sistemas utilizados para a representação da linguagem de indexação e a necessidade do usuário. Conforme Silva (2010, p. 46), 
os tesauros e os vocabulários controlados junto com os sistemas de classificação simbolizam as linguagens documentárias mais conhecidas. A Classificação Decimal de Dewey - CDD, a Classificação Decimal Universal - CDU, a Library of Congess - LC e a Colon Classification de Ranganathan são instrumentos utilizados para simbolizar, por meio de números, letras e categorias, o conteúdo dos documentos. No âmbito jurídico, a CDU e a Classificação Decimal de Direito são as mais comuns.

A Classificação Decimal de Direito", também conhecida como "Classificação de Doris" e utilizada por bibliotecas especializadas na área jurídica, foi criada por Doris de Queiroz Carvalho em 1932. Na área jurídica, há ainda vocabulários e tesauros, linguagens documentárias criadas para especialistas que atuam na área de Direito, utilizados na indexação, recuperação de informação e controle terminológico de documentações jurídicas e administrativas das áreas legislativas, doutrinárias e jurisprudenciais.

Esses vocabulários são utilizados como instrumentos de pesquisas na indexação de documentos e como ferramentas de gestão da informação e apoio aos profissionais da informação e construção de uma linguagem jurídica. A maioria é de livre acesso e pode ser consultada pelo público em geral. Entre eles, destacam-se as principais linguagens documentárias utilizadas na área jurídica (Quadro 1).

\begin{tabular}{|c|c|}
\hline $\begin{array}{ll}\text { Tesauro Jurídico } \\
\text { da } & \text { Justiça } \\
\text { Federal } & \end{array}$ & $\begin{array}{l}\text { Contém uma lista alfabética de modificadores e terminologias de } \\
\text { Direito de diversas áreas da Justiça Federal. Apresenta as seguintes } \\
\text { características: descrição e padronização de termos, categorização } \\
\text { de descritivos e não descritivos, relações entre conceitos e tem o } \\
\text { objetivo de garantir melhores relações entre sistemas e bases de } \\
\text { dados. } \\
\text { hisponível } \\
\text { http://www.cjf.jus.br/biblioteca/apresentacao tesaurojuridico.asp }\end{array}$ \\
\hline \begin{tabular}{l}
\multicolumn{2}{l}{ Tesauro Jurídico } \\
do Superior \\
Tribunal de \\
Justiça \\
vocabulário \\
jurídico \\
controlado STJ
\end{tabular} & $\begin{array}{l}\text { Linguagem padronizada para facilitar e dar maior credibilidade na } \\
\text { recuperação da informação. Ele é mantido pela Secretária de } \\
\text { Jurisprudência do STJ. Possui descritores (termos autorizados), não } \\
\text { descritores (termos não autorizados) e modificadores (termos } \\
\text { usados para esclarecer ou limitar os descritores), utiliza relações de } \\
\text { equivalência, hierárquicas, associativas e uma que eles dominam de } \\
\text { polierarquia, que admite que um termo específico tenha relação com } \\
\text { mais de um termo genérico. Disponível em: } \\
\text { http://www.stj.jus.br/scon/thesaurus/ }\end{array}$ \\
\hline
\end{tabular}

${ }^{1}$ Classificação Decimal de Direito está disponível no site: http://legislacao.planalto.gov.br/cddir/cddir.nsf. 


\begin{tabular}{|c|c|}
\hline $\begin{array}{l}\text { Vocabulário } \\
\text { Controlado da } \\
\text { USP }\end{array}$ & 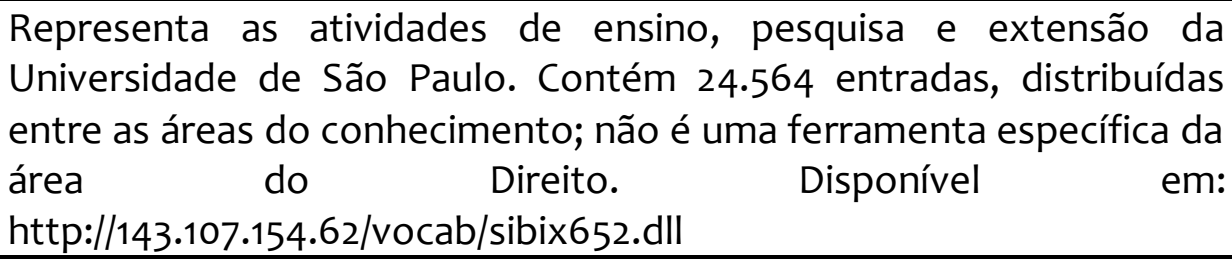 \\
\hline $\begin{array}{l}\text { Tesauro } \\
\text { Tribunal } \\
\text { Superior } \\
\text { Eleitoral }\end{array}$ & $\begin{array}{l}\text { Tem como objetivo padronizar e uniformizar a linguagem dos } \\
\text { conteúdos e da indexação de documentos. Possui ferramentas que } \\
\text { dão suporte à busca das informações necessárias. Disponível em: } \\
\text { http://www.tse.gov.br/hotSites/CatalogoPublicacoes/pop_up/tesaur } \\
\text { o.html }\end{array}$ \\
\hline TEJUT & $\begin{array}{l}\text { Tesauro do Direito do Trabalho, é mantido pelo Serviço de } \\
\text { Documentação do Tribunal Regional do Trabalho. Sua criação foi } \\
\text { fundamentada em palavras que são utilizadas no Tribunal como } \\
\text { chave de recuperação e em termos mais significativos para serem } \\
\text { usados como descritores. } \\
\text { http://www.infolegis.com.br/TEJUT.pdf } \\
\end{array}$ \\
\hline WEBTHES & $\begin{array}{l}\text { Possui acesso e a consulta em dois tesauros: THES e VCBS, ambos } \\
\text { mantidos pelo Senado Federal. O THES tem o objetivo de indexar e } \\
\text { recuperar documentos e informações contidas em bases de dados } \\
\text { como o NJUR, que possui normas jurídicas federais; o DISC, onde } \\
\text { encontramos discursos de deputados e senadores; e o MATE, que } \\
\text { contém matérias em tramitação no Congresso Nacional. Disponível } \\
\text { em: http://legis.senado.gov.br/webthes/ }\end{array}$ \\
\hline VCBS & $\begin{array}{l}\text { Criado como ferramenta para análise de documentos e informações } \\
\text { de bases de dados, como artigos de jornais, periódicos, livros, obras } \\
\text { raras, monografias, entre outros. Desenvolvido para indexação e } \\
\text { recuperação de fontes doutrinárias. Disponível em: } \\
\text { http://legis.senado.gov.br/webthes/. }\end{array}$ \\
\hline
\end{tabular}

Quadro 1 - Linguagens documentárias utilizadas na área jurídica

As novas tecnologias de informação permitem maior precisão, qualidade de pesquisa e acessibilidade. Hoje, as bases de dados jurídicas, os vocabulários controlados e os tesauros eletrônicos são utilizados por profissionais que atuam em diversas vertentes ligadas ao Direito, como pesquisadores, bibliotecários, gestores da informação, documentalistas, arquivistas, indexadores, advogados, juízes, estudantes e outros profissionais. Tais ferramentas são fundamentais para garantir a qualidade da indexação e a recuperação da informação na área jurídica. 


\section{Fontes de informação jurídica para a pesquisa em Direito}

Fontes de informação são produtos e serviços que têm o objetivo de transmitir, de forma mais acessível e simplificada, informações seguras e confiáveis para o usuário. Para Silva e Rolim (2009, p. 30) “cada fonte de informação jurídica possui características que atendem a uma superestrutura particular, sendo indispensável que o bibliotecário tenha conhecimento da linguagem da área do Direito em que atua e, também, domine a estrutura textual dos documentos jurídicos". A identificação da estrutura textual dos documentos contribui para a compreensão das ideias principais do texto.

As fontes de informação podem ser classificadas em fontes primárias, secundárias e terciárias.

Para Barros (2004, p. 208), "as fontes primárias são aquelas que contêm a informação apresentada em forma original, inteira, isto é, não condensada nem resumida, não selecionada nem abreviada". Ou seja, são informações originais, representadas por livros, revistas, teses, dissertações, artigos de periódicos, patentes, entre outras.

Já as fontes secundárias, segundo Sena (2013, p. 56), "são aquelas com a finalidade de guiar o usuário para as fontes primárias". Podemos dizer que é um produto das fontes que é reorganizado, como os dicionários, enciclopédias, resumos e bases de dados.

Barros (2004, p. 208) define as fontes terciárias como: “aquelas que têm a função de orientar o pesquisador para as fontes primárias e secundárias". Dessa forma, tornam as fontes primárias e secundárias mais acessíveis aos usuários. É o caso das bibliografias, índices, diretórios e também das bibliotecas e dos centros de informação.

As fontes de informação também podem ser divididas em formais e informais. Fontes formais são aquelas que têm uma forma, são representadas em suportes físicos ou digitais desde que as fontes sejam estruturadas. Quanto às fontes informais, são aquelas que não têm estrutura, a informação é transmitida oralmente (conferência, aula) e em suporte eletrônico, na Internet (chats, correio eletrônico, listas de discussão). (CARVALHO, 2001). 
De acordo com Barros (2004, p. 202),

as fontes do Direito constituem a ordem jurídica de uma sociedade e formam o alicerce da Ciência do Direito. As fontes materiais ou sociológicas são representadas a partir da filosofia e história do Direito, como técnicas, política, condutas e costumes de uma sociedade. Entretanto, as fontes formais são aquelas representadas pelos meios que o Direito é manifestado, como as leis, doutrina, jurisprudência, princípios gerais, etc.

Schneider e Wackerritt (1992 apud BARROS, 2004, p. 203) também apontam as fontes históricas, isto é, aquelas que serviram originariamente de base ao nosso Direito (Direito Romano, Direito Canônico, Direito Americano, Direito Francês e Direito Alemão). As fontes formais se subdividem em fontes principais (Legislativas) e fontes secundárias (doutrinárias, jurisprudenciais, analogia, costume, etc.). Conforme Silva (2010, p.70),

na atuação operacional do bibliotecário jurídico as fontes legislativas, doutrinárias e jurisprudenciais são as mais relevantes e produzem a chamada documentação jurídica, estando presente na maioria dos acervos jurídicos.

Segundo Barros (2004, p. 203) "a lei é a fonte principal do Direito". As fontes legislativas representam as normas superiores que são os conjuntos, decretos e projetos de leis (federais, estaduais e municipais), acórdãos, tratados e medidas provisórias; e as normas inferiores, que são as deliberações, comunicados, resoluções, circulares, etc. E também as normas de conduta, direitos, deveres e atos legais previstos na Constituição Federal.

Silva (2010, p. 71) destaca que

quanto às fontes legislativas é significativo identificar e distinguir os atos federais, municipais e estaduais, bem como entender os trâmites das normas legislativas, além de manter-se atento às revogações, alterações e surgimento de novas leis/normas, evitando que o operador do Direito trabalhe com normas desatualizadas e/ou revogadas. 
Para a recuperação da informação das fontes legislativas, primeiro é necessário identificar se a norma ou projeto de lei está no âmbito federal, estadual ou municipal, e de que órgão essa lei se origina, para depois ser feita a busca em bases de dados oficiais.

Já as fontes doutrinárias são simbolizadas por livros, monografias, artigos científicos, trabalhos apresentados em eventos, pareceres jurídicos e por decisões e comentários de leis. Para Barros (2004, p. 203), "é a interpretação de autores, juristas e escritores acerca de uma norma ou decisão jurídica".

No âmbito das fontes doutrinárias é recomendável que o profissional bibliotecário conheça os livros clássicos da área de atuação dos seus usuários (civil, penal, comercial, tributários, entre outras) e mantenha o acervo atualizado em relação às novidades e discussões das respectivas áreas. (SILVA, 2010, p. 71).

É nas fontes doutrinárias e jurisprudenciais que o bibliotecário sentirá, com mais ênfase, a necessidade de conhecer e compreender a terminologia da área para indexar e recuperar, de modo satisfatório, o conteúdo dos artigos, monografias, pareceres e acórdãos.

As fontes jurisprudenciais são representadas pelas decisões judiciais dos juízes e tribunais, acórdãos, resoluções e sentenças. Também é através dela que conhecemos as situações dos julgamentos e as soluções que devemos tomar diante destes.

É interessante o bibliotecário conhecer a competência dos tribunais, bem como os tipos de recursos, além de entender o significado das decisões dos magistrados, porque, no momento de representação e recuperação do acórdão, a menção do provimento ou improvimento da decisão poderá ser a causa determinante para o usuário consultá-lo ou não. (SILVA, 2010, p. 71)

É importante, então, que o profissional de direito ou bibliotecário jurídico tenha entendimento acerca dos conteúdos dos acórdãos e significados das sentenças para registro dos seus pareceres e para indexação e recuperação da informação jurisprudencial.

Existem ainda outras fontes secundárias, como os princípios gerais do Direito, costumes, analogia, normas de conduta, entre outras. Essas fontes são estudadas com mais profundidade a partir da literatura e princípios específicos de cada área. 
Fontes de informação jurídica podem ainda ser representadas por pessoas, empresas, centros de informação e documentação, escritórios de advocacia, cartórios, órgãos, instituições públicas e, também, por meios eletrônicos, como sistemas e bases de dados, sites jurídicos, portais, revistas eletrônicas e bibliotecas tradicionais e digitais. Ou seja, qualquer meio sendo físico ou virtual, que transmita informação jurídica.

O conhecimento de todos esses tipos de fontes e os locais em que se encontram é essencial para atuação do bibliotecário e documentalista jurídico. É preciso, além de conhecer os modelos de fontes de informação jurídica e as tipologias documentais jurídicas, saber extrair informações úteis e confiáveis para o bom desempenho do seu trabalho.

Para auxiliar na recuperação da informação e filtrar buscas, o conhecimento de locais como sistemas e bases de dados, sites de informação jurídica, revistas eletrônicas e sites oficiais públicos, é essencial para todos os profissionais que atuam no âmbito do Direito. Destacam-se alguns exemplos de fontes de informação jurídica divididos em categorias de acordo com o tipo de fonte, documentação e informação procurada.

\begin{tabular}{|c|c|}
\hline $\begin{array}{l}\text { Sistemas e Bases } \\
\text { de Dados }\end{array}$ & $\begin{array}{l}\text { SICON: Sistema de Informação do Congresso Nacional que permite } \\
\text { que se façam pesquisas básicas e avançadas, buscando e filtrando o } \\
\text { assunto em locais como: Agência Senado, Discursos de Senadores, } \\
\text { Legislação Federal, Recortes de Jornais, Repositórios, entre outros. } \\
\text { Disponível em: http://legis.senado.gov.br/sicon/ } \\
\text { SIJUT: Sistema de Informações Jurídico-Tributárias. Nele, é possível } \\
\text { acessar atos legais nas versões: anotada, compilada e original. } \\
\text { Disponível } \\
\text { http://sijut.fazenda.gov.br/netahtml/sijut/Pesquisa.htm } \\
\text { DATAJURIS: a base de dados jurídicos, especializada em informação } \\
\text { legislativa (jornais oficiais e boletins) e jurisprudencial (pesquisa } \\
\text { global por campos ou tesauros). Disponível em: www.datajuris.pt. } \\
\text { INFOLEGIS: reúne manuais de pesquisa do sistema jurídico e textos } \\
\text { de legislação brasileira e estrangeira. Disponível em: } \\
\text { www.infolegis.com.br. }\end{array}$ \\
\hline $\begin{array}{l}\text { Portais e } \\
\text { Revistas } \\
\text { Eletrônicas }\end{array}$ & $\begin{array}{l}\text { CONJUR: a revista eletrônica Consultor Jurídico oferece informação } \\
\text { sobre direito e justiça, que também edita Anuários da Justiça, como } \\
\text { Tribunais Superiores, Justiça Federal, Tribunais Regionais do Trabalho } \\
\text { e Justiça Estadual. Seu objetivo é ser fonte de informação e pesquisa }\end{array}$ \\
\hline
\end{tabular}




\begin{tabular}{|c|c|}
\hline & $\begin{array}{l}\text { para profissionais que atuam na área jurídica. Disponível em: } \\
\text { www.conjur.com.br. } \\
\text { Âmbito Jurídico: portal jurídico que contém informações e serviços } \\
\text { para pesquisa de doutrina e informações judiciais. Também organiza } \\
\text { Jornadas e Simpósios para profissionais e estudantes de Direito. } \\
\text { Disponível em: www.ambito-juridico.com.br. } \\
\text { Direito do Estado: portal multimídia de informações jurídicas e site } \\
\text { oficial do Instituto Brasileiro de Direito Público. Seu diferencial são os } \\
\text { conteúdos em multimídia, como os recursos de vídeo, áudio e textos } \\
\text { de Direito Público, com acesso aberto e gratuito. Possui também as } \\
\text { revistas eletrônicas: REDE, REDAE e RERE e uma biblioteca virtual. } \\
\text { Disponível em: www.direitodoestado.com.br. }\end{array}$ \\
\hline Sites & 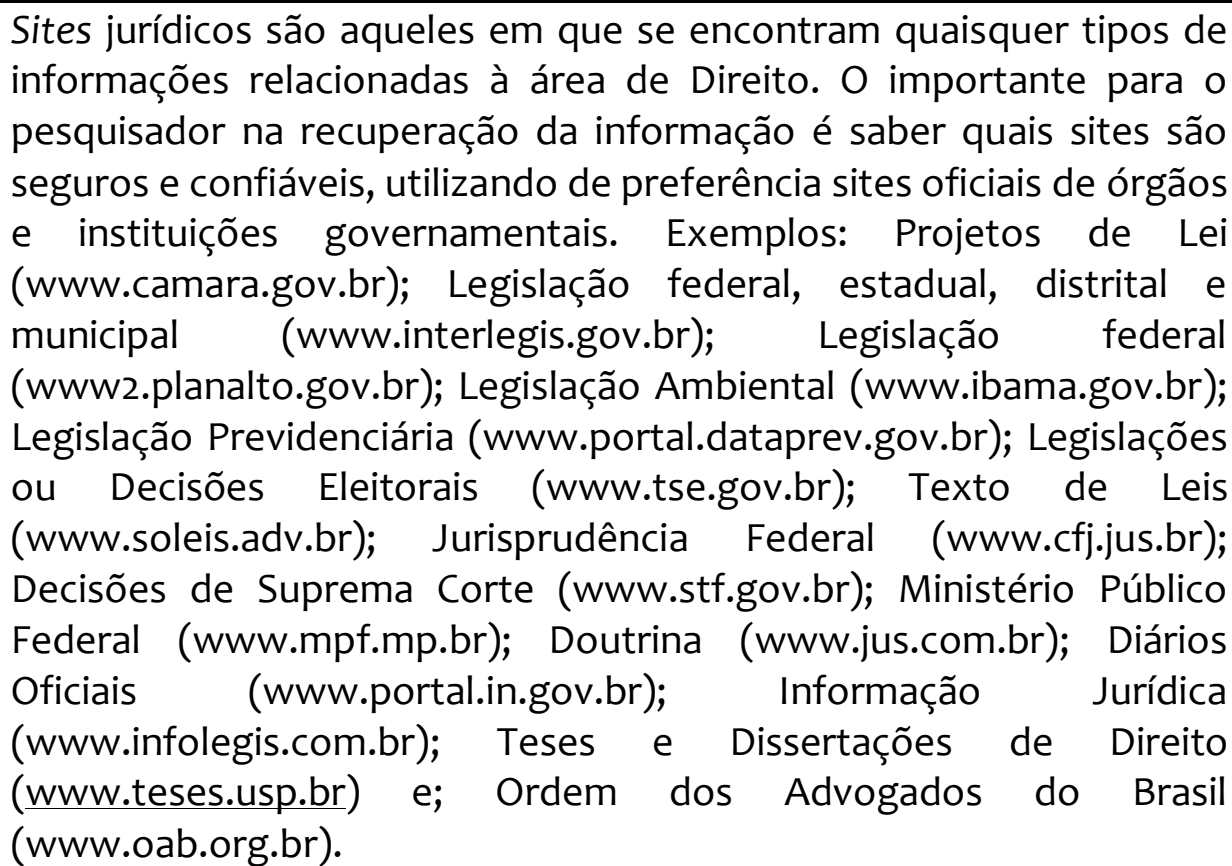 \\
\hline $\begin{array}{l}\text { Bibliotecas } \\
\text { Virtuais e } \\
\text { Digitais }\end{array}$ & $\begin{array}{l}\text { Biblioteca do Conselho de Justiça Federal: são disponibilizados livros, } \\
\text { documentos e artigos de periódicos sobre informações jurídicas. É } \\
\text { possível filtrar as buscas fazendo consulta ao acervo geral, à coleção } \\
\text { de materiais especiais, bibliográfica da Justiça Federal, atos } \\
\text { normativos, códigos, além do Tesauro Jurídico da Justiça Federal. } \\
\text { Disponível em: http://www.cjf.jus.br/bibliotecal } \\
\text { A Biblioteca do Senado, ou Biblioteca Acadêmico Luiz Viana Filho tem } \\
\text { um acervo específico em ciências sociais e de acordo com seu } \\
\text { institucional: "tem a missão de fornecer o suporte informacional } \\
\text { necessário às atividades desenvolvidas no âmbito do Senado Federal } \\
\text { e do Congresso Nacional”. } \\
\text { http://www.senado.gov.br/senado/bibliotecal } \\
\text { Biblioteca Digital do Supremo Tribunal Federal disponibiliza }\end{array}$ \\
\hline
\end{tabular}




\begin{tabular}{|c|c|}
\hline & $\begin{array}{l}\text { informações e documentos de diferentes suportes: livros, } \\
\text { documentos, fotografias, vídeos, entrevistas, áudios, vídeos, peças } \\
\text { de museus, entre outros. De acordo com o site oficial, atualmente } \\
\text { estão disponíveis seis coleções: Obras Completas de Rui Barbosa, } \\
\text { Obras Raras, Domínio Público, Publicações Institucionais, Produção } \\
\text { Intelectual de Ministros e Servidores e Revista O Direito. Disponível } \\
\text { em: http://www.stf.jus.br/portal/biblioteca/ } \\
\text { Biblioteca Digital Jurídica do Superior Tribunal de Justiça, que possui } \\
\text { informações e documentos jurídicos como: capítulos de livros e } \\
\text { periódicos, teses, dissertações, discursos, palestras e decisões } \\
\text { jurisprudenciais. } \\
\text { http://stj.jus.br/portal_stj/publicacao/engine.wsp?tmp.area=353 } \\
\text { Biblioteca Digital Brasileira de Teses e Dissertações. De acordo com o } \\
\text { Ibict, que coordena o projeto da BDTD, a biblioteca integra os } \\
\text { sistemas de informação de teses e dissertações existentes nas } \\
\text { instituições de ensino e pesquisa brasileiras, além de estimular o } \\
\text { registro e a publicação de teses e dissertações em meio eletrônico. } \\
\text { Este projeto também possibilita que a comunidade brasileira } \\
\text { publique suas teses e dissertações produzidas no país e no exterior, } \\
\text { dando maior visibilidade à produção científica nacional. Disponível } \\
\text { em: http://bdtd.ibict.br/ }\end{array}$ \\
\hline $\begin{array}{l}\text { Órgãos e } \\
\text { Instituições } \\
\text { Públicas }\end{array}$ & $\begin{array}{l}\text { Todos os órgãos públicos, sendo de cargo jurídico ou não, precisam } \\
\text { de assessoria, pois produzem informações. O órgão do Poder } \\
\text { Legislativo, responsável por elaborar leis é o Congresso Nacional, } \\
\text { onde também se encontra a Câmara dos Deputados e o Senado } \\
\text { Federal. } \\
\text { A Câmara dos Deputados é responsável por atos internos e demais } \\
\text { documentos. No site do Senado Federal é possível encontrar } \\
\text { informações sobre a constituição, emendas, decretos legislativos, leis } \\
\text { e resoluções. } \\
\text { Já o órgão do Poder Executivo compreende os órgãos da Presidência } \\
\text { da República, Secretarias, Ministérios, Departamentos, Conselhos, } \\
\text { Superintendências, Universidades, Empresas Públicas, Fundações, } \\
\text { etc., e grande parte dos agentes e servidores públicos que atuam } \\
\text { nesses órgãos têm a informação jurídica como instrumento de } \\
\text { trabalho, razão pela qual, tais instituições assumem um papel } \\
\text { importante como fontes geradoras de informação jurídica. } \\
\text { A Imprensa Nacional pertence ao Poder Executivo e é uma das mais } \\
\text { importantes instituições de acesso e disseminação da informação } \\
\text { pública federal. De acordo com a própria Imprensa Nacional, sua } \\
\text { missão é preservar as informações oficiais contribuindo para a } \\
\text { cidadania e manter a memória da imprensa brasileira, permitindo o }\end{array}$ \\
\hline
\end{tabular}


acesso e a segurança das informações, credibilidade, ética, cultura e transparência. Disponível em: http://portal.in.gov.br/.

O órgão do Poder Judiciário compreende:

- Supremo Tribunal Federal, órgão de instância máxima da justiça, que contém informações sobre regimento, julgamentos, jurisprudência, publicações, imprensa e acesso à informação. Disponível em: www.stf.gov.br

- Superior Tribunal de Justiça é responsável pela interpretação de leis federais de acordo com os princípios constitucionais. Disponível em: http://www.stj.jus.br/sites/STJ

- Justiça Federal: tem a missão de julgar e condenar como autora ou ré, questões que envolvem o Poder Judiciário da União. Ela é divida em $1^{a}$ instância, que compreende uma Seção Judiciária em cada estado, e a $2^{\text {a }}$ instância, composta por cinco Tribunais Regionais Federais. Todas as seções são regidas por juízes federais que julgam questões da Justiça Federal. Disponível em: www.jf.jus.br.

- Justiça do Trabalho, responsável por julgar ações trabalhistas e empregatícias, e outros casos relacionados ao trabalho. Os órgãos que compõem a Justiça do Trabalho são o Tribunal Superior do Trabalho, Tribunal Regional do Trabalho e Juízes do Trabalho. Disponível em: www.tst.jus.br.

- Justiça Militar, conhecida também como Superior Tribunal Militar, julga crimes militares e previstos na lei. Disponível em: www.stm.jus.br.

Existem também alguns órgãos essenciais à justiça; os principais são:

- Ministério Público: sua função é promover a justiça. Seus principais atos são os pareceres dos promotores da justiça, além de ser uma arma de defesa nacional, exercendo a defesa da ordem jurídica, do regime democrático, dos interesses sociais e individuais, entre outros direitos constitucionais. Disponível em: http://www.mpf.mp.br/.

- Defensoria Pública: sua missão é garantir aos necessitados o conhecimento e a defesa de seus direitos. Disponível em: www.dpu.gov.br.

- Advocacia-Geral da União: representa a União no campo judicial e extrajudicial, além de prestar consultoria e assessoramento jurídico ao poder executivo, garantindo a execução de políticas públicas. Disponível em: www.agu.gov.br.

- Advocacia: é uma profissão exercida pelo advogado, profissional bacharel em Direito, que tem como competência a administração da justiça, assegurando e exercendo justiça perante a lei. Para se tornar um advogado no Brasil é necessário, além da graduação 


\begin{tabular}{|c|c|}
\hline & $\begin{array}{l}\text { em Direito, estar regularmente inscrito na OAB. } \\
\text { - A OAB é uma instituição que representa e permite que os } \\
\text { profissionais advogados exerçam suas atividades e assegurem } \\
\text { seus atos perante a lei. Disponível em: www.oab.org.br. }\end{array}$ \\
\hline $\begin{array}{l}\text { Livrarias e } \\
\text { Editoras }\end{array}$ & 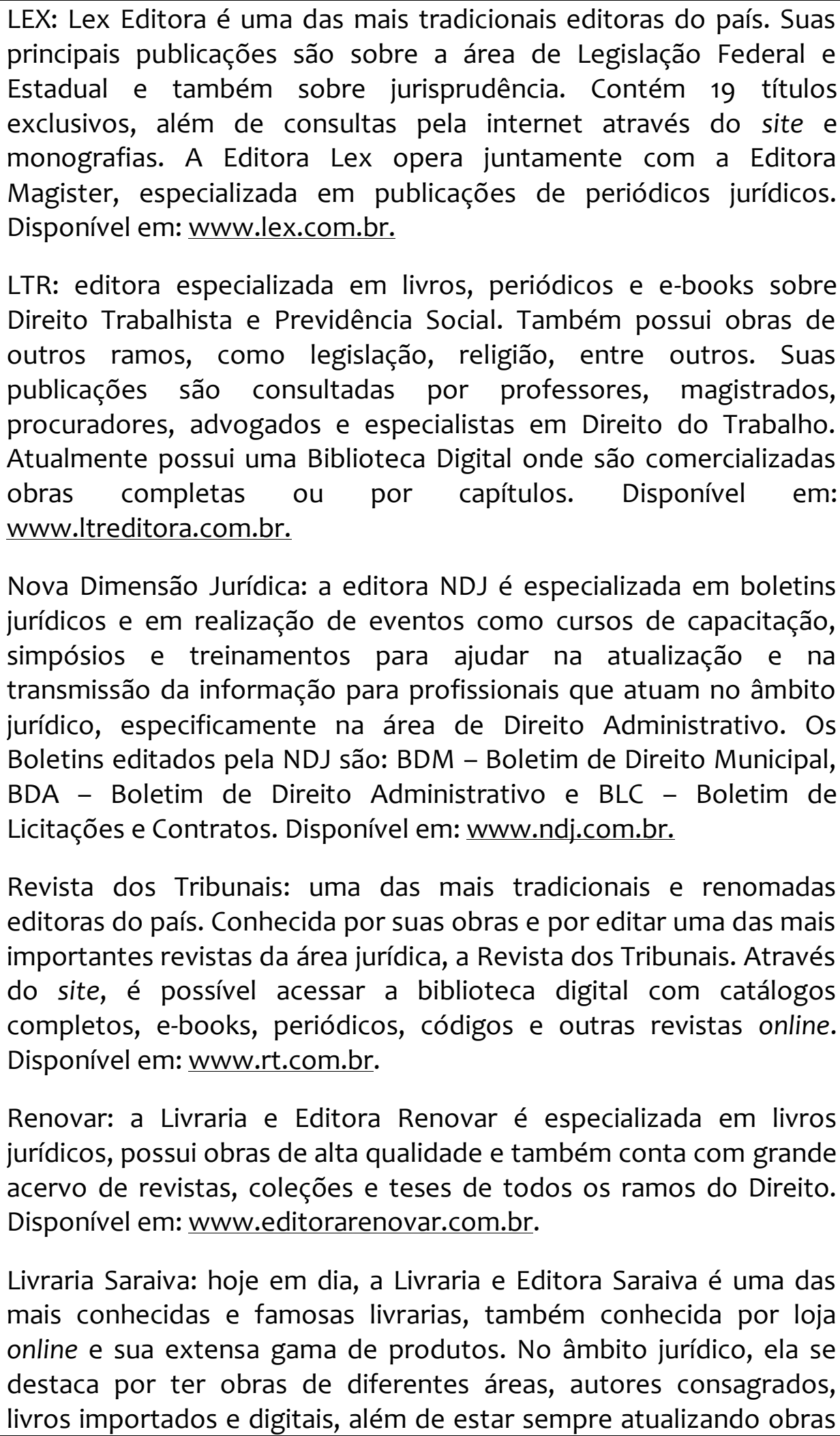 \\
\hline
\end{tabular}




\begin{tabular}{|c|c|}
\hline & $\begin{array}{l}\text { importantes. Disponível em: www.livrariasaraiva.com.br. } \\
\text { ATLAS: a Livraria e Editora Atlas produz conteúdo de grandes autores } \\
\text { nacionais e internacionais do ramo do Direito, incluindo os manuais } \\
\text { de Legislação Atlas, livros para concurso, e-books e o famoso Código } \\
\text { Atlas. Disponível em: www.editoraatlas.com.br. }\end{array}$ \\
\hline Cartórios & $\begin{array}{l}\text { Barros (2004, p. 222) afirma que "cartório é o lugar onde os } \\
\text { serventuários de justiça oficiam e arquivam as notas públicas, títulos } \\
\text { e documentos, processos e livros pertencentes ao seu arquivo, } \\
\text { constituindo-se, portanto, de agentes portadores de informação } \\
\text { jurídica, também conhecida como escritórios de notários ou } \\
\text { escrivães." De acordo com o Senado Federal, cartórios são } \\
\text { concessões públicas e existem dois tipos: os cartórios judiciais ou } \\
\text { varas, responsável por processos judiciais; e os extrajudiciais, que são } \\
\text { vinculados a um tabelião e oficiais de registro. } \\
\text { Assim, existem Cartórios de Registro Civis de pessoas Naturais e } \\
\text { Jurídicas, de Registros de Títulos e Documentos, Registro de Imóveis, } \\
\text { Tabelião de Notas e de Protesto de Título. Disponível em: } \\
\text { http://www.senado.gov.br/ e http://www.guiadedireitos.orgl }\end{array}$ \\
\hline $\begin{array}{l}\text { Grupos de } \\
\text { Documentação } \\
\text { Jurídica }\end{array}$ & $\begin{array}{l}\text { Os Grupos de Informação e Documentação Jurídica (GIDJ's) foram } \\
\text { criados por bibliotecários, documentalistas e outros profissionais que } \\
\text { atuam na área de informação e documentação jurídica, a fim de } \\
\text { aprimorar seus conhecimentos através da troca de experiências, } \\
\text { divulgação de trabalhos, eventos, cursos, programas de capacitação } \\
\text { e metodologias de trabalhos relacionados à área jurídica. A maioria } \\
\text { desses profissionais atua em escritórios de advocacia, centros de } \\
\text { informação e documentação jurídica, instituições públicas, tribunais e } \\
\text { bibliotecas, com cargos de consultores, arquivistas, processadores } \\
\text { técnicos, documentalistas, bibliotecários e diretores. Exemplos } \\
\text { desses Grupos: } \\
\text { Grupo de Informação e Documentação Jurídica de São Paulo: } \\
\text { http://gidjsp.com.br/ } \\
\text { Grupo de Informação e Documentação Jurídica do Rio de Janeiro: } \\
\text { http://gidjri.com.br/ }\end{array}$ \\
\hline
\end{tabular}

Quadro 2 - Fontes de Informação Jurídica

Observa-se que as Fontes de Informação Jurídica estão disponíveis em diversas instituições, bases de dados, sites, bibliotecas, portais, livrarias, editoras, cartórios, escritórios, pessoas, entre outros. Para a recuperação de informações precisas e seguras, é preciso explorar os recursos disponíveis em cada fonte, criar estratégias de busca e procurar informações em sites oficiais e confiáveis. 
No caso do bibliotecário jurídico, é essencial o conhecimento das Fontes de Direito, tipologia de documentos jurídicos, além de saber manusear e identificar os recursos disponíveis para essa recuperação, a fim de garantir a satisfação do usuário.

\section{Considerações Finais}

A Ciência da Informação, ciência interdisciplinar, possibilita que o profissional se especialize e atue em diversas áreas, entre elas o Direito. O profissional da informação desempenha um papel fundamental na organização da informação e na construção do conhecimento. Ao seguir carreira na área jurídica, é necessário estudo e especialização da área de Direito, pois se trata de uma área com especificidades e terminologias peculiares.

Este artigo não teve a pretensão de esgotar todas as ferramentas disponíveis para a gestão e recuperação da informação jurídica; o propósito foi reunir algumas destas ferramentas com o intuito de contribuir tanto com os profissionais da informação que pretendem atuar neste cenário como com os estudantes e pesquisadores da área do Direito que almejam recuperar informações confiáveis nesta área.

As fontes de informação na área jurídica podem ser representadas em meios físicos (empresas, escritórios de advocacia) e virtuais (sistemas, sites, revistas eletrônicas); cabe ao pesquisador identificar onde encontrar o tipo de informação que necessita. Alguns locais como as bibliotecas públicas especializadas na área do Direito, também são grandes fontes de informação, por reunirem tanto fontes impressas como eletrônicas, além de possuírem grande diversidade de livros, revistas, periódicos e de oferecerem serviços que auxiliam o pesquisador jurídico.

A pesquisa satisfatória no âmbito jurídico depende de conhecimentos prévios das fontes de Direito, das tipologias documentais e das terminologias jurídicas. Buscar informações em fontes específicas e seguras também é essencial; cabe ao profissional o estudo das diversas fontes de informação para o melhor desempenho do seu trabalho e desenvolvimento de pesquisas. 


\section{Referências}

ATIENZA, Cecília Andreotti. Documentação jurídica: introdução à análise e indexação de atos legais. Rio de Janeiro: Achiamé, 1979.

BARROS, Lucivaldo. Fontes de informação jurídica. In: PASSOS, Edilenice (Org.). Informação jurídica: teoria e prática. Brasília: Thesaurus, 2004, p. 201-225.

CARVALHO, Katia. Disseminação da Informação e Informação de Inteligência Organizacional. DataGramaZero, Rio de Janeiro, v.2, n.3, p.00-00, jun. 2001.

FUJITA, Mariângela Spotti Lopes. A leitura documentária na perspectiva de suas variáveis: leitor-texto-contexto. DataGramaZero, Rio de Janeiro, v.5 n.4, ago. 2004.

GESNER, Conrad. Bibliotheca universalis. Tiguri: Christophorvm Froschouerum, 1545. $\mathrm{KOCH}$, Ingedore G. Villaça. Desvendando os segredos do texto. 5. ed. São Paulo: Cortes, 2006.

KOCH, Ingedore G. Villaça. Desvendando os segredos do texto. 5. ed. São Paulo: Cortes, 2006.

LIMA, João Alberto de Oliveira; CUNHA, Murilo Bastos da. Tratamento da informação Legislativa e Jurídica: perspectiva histórica. Senatus, Brasília, v. 6, n. 2, p. 33-38, out. 2008.

PASSOS, Edilenice; BARROS, Lucivaldo Vasconcelos. Fontes de informação para pesquisa em Direito. Brasília: Briquet de Lemos, 2009.

SENA, Alexandre. Fontes de Informação utilizadas pelos discentes do mestrado do Instituto de Educação Matemática e Científica da UFPA (IEMCI/UFPA). Biblionline. João Pessoa, v.9, n.1, p.52-60, 2013.

SILVA, Andréia Gonçalves. Fontes de informação jurídica: conceitos e técnicas de leitura para o profissional da informação. Rio de Janeiro: Interciência, 2010. 248p.

SILVA, Andréia Gonçalves; ROLIM, Maria Lúcia de Borba. Organização das fontes de informação jurídica na perspectiva do GIDJ/SP. Revista CRB-8 Digital. São Paulo, v.2, n.2, p.27-33, set. 2009. Disponível em: <http://revista.crb8.org.br>. Acesso em: 24 abr. 2014. 
Recebido em: 05/05/2015 Aprovado em: 19/04/2016

Universidade do Estado de Santa Catarina - UDESC

Centro de Ciências Humanas e da Educação - FAED

Revista PerCursos

Volume 17 - Número 33 - Ano 2016

revistapercursos@gmail.com 